\title{
ИСКУССТВОВЕДЕНИЕ
}

\author{
УДК: $394.2+7.04$ \\ ФЕНОМЕН ТРАДИЦИОННОГО КИТАЙСКОГО ОРНАМЕНТАЛЬНОГО ИСКУССТВА \\ ЦЗЯНЬЧЖИ: ТРАДИЦИИ И СОВРЕМЕННОСТЬ
}

Мартынова Н.В. кандидат педагогических наук, дочент кафедры дизайна, ДПИ и этнокультуры, Тихоокеанский государственный университет,

Россия, г. Хабаровск

Слипецкая Д.Р.

студентка кафедры дизайна, ДПИ и этнокультуры, Тихоокеанский государственный университет,

Россия, г. Хабаровск

\section{THE PHENOMENON OF TRADITIONAL CHINESE ORNAMENTAL ART “JIANZHI": TRADITIONS AND NOWADAYS}

\author{
Martynova N.V. \\ PhD, Associate professor at the Department of design, \\ applied arts and ethno culture, Pacific National University \\ Khabarovsk, Russia \\ Slipetskaya D.R. \\ Pacific National University, \\ Khabarovsk, Russia \\ DOI: $10.31618 /$ asj.2707-9864.2020.1.37.5
}

Аннотация. Статья обращена к феномену многотысячелетнего народного искусства Китая. Благопожелательная символика цзяньчжи, китайского искусства ручного вырезания из бумаги узоров, исходит от орнаментальных образов, а те, в свою очередь, отражают национальные мифологические и религиозные представления, жизненный уклад, объективную реальность и являются универсальным языком для познания народного менталитета. Народные мастера древнего Китая, вложив в декоративные композиции цзяньчжи символическое значение с функцией оберега, желали ее владельцам счастливой и долгой благополучной жизни. Семантика «бумажного кружева» многогранна и глубока, а традиция его использования в качестве декора, сопровождающего значимые для человека дни праздников и торжеств, актуальна и сегодня. Все это позволяет утверждать, что именно этот уникальный вид народного искусства, продолжая своѐ активное развитие в различных формах в современном мире, стал узнаваемым «фирменным стилем» Китая.

Abstract. The article considers the phenomenon of Chinese ornamental art, called "jianzhi". Well-being in symbols of this art, Chinese paper-cutting, comes from ornamental figures, and they, in turn, reflect national mythological and religious ideas, life style and reality. It is a universal language of national mentality. Ancient Chinese with special attitude created paper compositions, because they believed that it is an amulet. That's why their semantics is so different and deep to take the paper-cutting works, also famous as "paper-lace" as national pride, which continue its development nowadays. All this allows claiming that this unique type of folk art, continuing the active development in various forms in the modern world, became recognizable "logo" of China.

Ключевые слова: цзяньчжи, благопожелательные символы, орнаментальное искусство Китая, вырезание из бумаги, народный мастер.

Keywords: "jianzhi” art, symbols of well-being, ornamental art of China, paper-cutting, craftsman.

Введение. Народное искусство страны - это область, исконно связанная с хозяйственнобытовым укладом и мифологическим сознанием народа. Орнамент в народном искусстве есть умелое отражение окружающей действительности, язык народа, символика помогающая познать тайны древней старины, в основе которой лежат традиционные верования, сцены повседневной жизни, народное мировоззрение, вера в благосклонность судьбы, и надежда на долгую счастливую жизнь. Термин «благопожелание» в народной культуре Китая объединил в себе целый ряд понятий, среди которых центральное место занимают: счастье, богатство, карьера, долголетие, радость, называемые в конфуцианской культуре «пять компонентов полного счастья», которые стали главными темами китайского орнамента. В древнекитайском классическом трактате «Чжуанцзы» это понятие дословно переводится на русский язык, как «счастливый баран». Объясняется тем, что древние китайцы вели кочевой образ жизни, и, как следствие, отара жирных баранов являлась великим достижением и трактовалась как «счастливое, благое» событие. 
В качестве основных методов исследования были использованы следующие:

сравнительный метод метод лингвистического анализа, метод интерпретации, исторический метод, а также метод наблюдения.

Анализ. Многообразие видов, техник и приѐмов народного искусства не может не удивлять, а мифопоэтические образы, есть не что иное, как зашифрованное в орнаменте послание потомкам, глубина их семантики и художественная выразительность создают такое многогранное явление, как орнаментальное декоративноприкладное искусство, создаваемое и передаваемое народными мастерами из поколения в поколение. Китайская нация сохранила богатейшую орнаментальную культуру в условиях закрытости страны, выработала собственную уникальную манеру декорирования изделий. Разнообразие в китайском орнаменте ценится больше, чем композиционная строгость. Так, элементы в композиции орнамента могут симметрично чередоваться, но их размер и пластичность будут различны. Китайские мастера в своем творчестве избегают прямых углов и линий не случайно, согласно традициям науки фэн-шуй, эти элементы собирают негативную энергию. Излюбленной формой орнаментальной композиции является круг - символ солнца и бесконечности. Порой орнаментальные композиции образуют причудливые формы, плавно обтекая плоскость. Богатство, яркость цветов заменяет законы перспективы и светотени. Древние китайцы объединили самые красивые, волшебные части некоторых животных и некоторые природные явления, такие как грозу, облако, радугу и молнию в образе дракона. Учѐный Ван Чун, живший во время династии Хань (206 г. до н.э. - 220 г. н.э.), говорит в своих трактатах: «У дракона рог оленя, голова верблюда, глаза зайца, шея змеи, тело с чешуей сазана, когти орла, лапы тигра, уши быка, живот беззубки». Его считают повелителем всех животных. Он связан с небом, а небо - это место, где живут божества; он способен изменять свой облик, а изменение - приспособление к условиям существования. Все волшебные качества объединились в драконе, поэтому в легендах считалось, что именно он является предвестником счастья. Дракон любит воду, а вода - это самое важное в жизни человека; он любит летать, а полѐт есть мечта о преодолении бедствий, об избавлении от трудного положения.

Птица Феникс (Фен-Хоан) - символ бессмертия. Го Пу, учѐный династии Цзинь в комментариях «Эр’я Ши няо» («Словарь о птицах») говорит: «...феникс - это птица, которая появляется при всеобщем благополучии на белом свете. У неѐ голова курицы, шея змеи, рот ласточки, спина черепахи, хвост рыбы, пятицветная окраска, еè высота - два метра». Древние китайцы объединили образы курицы, орла, аиста, ласточки, павлина в своѐм великолепии и природные явления - солнце и ветер в образе птицы Феникс. В эпосе «Шаньхай цзин» говорится: «На фениксе пять узоров: узор на головной части символизирует добродетель, узор на крыльях символизирует надлежащее поведение, узор на спине символизирует справедливость, узор на груди символизирует человеколюбие, узор на животе символизирует верность». Китайцы наделили птицу Фен-Хоан своими моральнонравственными идеалами и представлениями, поэтому она стала символом благодати. Эта птица благородна, любит солнце, имеет связь с небом, предвещает счастье, любит чистоту и красоту. Еѐ считают старшей из всех птиц, царицей пернатых. Также почитаются: черепаха (мудрость), журавль (верность и благородство), белый олень (благополучие). Эти и другие исконно народные благопожелательные символы красной нитью проходят через декоративное искусство Китая, наполняя его божественным звучанием.

Основная часть. Древнее народное искусство Китая - «цзяньчжи» (剪纸, jianzhi), ажурное вырезание из бумаги, является уникальным образцом традиционного декоративного творчества, по версии UNESCO отнесенное к числу мирового культурного наследия. Его альтернативное название - «бумажное кружево» отражено в легенде об истории возникновения данного искусства, которая гласит: «Однажды бедный каллиграф написал иероглиф 福 $(f u)$ «счастье», а жену настолько впечатлило творение мужа, что она вырезала этот иероглиф из красной бумаги, и наклеила его на окно, и после этого их дом оставили беды» [6]. Надо отметить, что эта традиция сохранилась в Китае по настоящее время. Искусство цзяньчжи отражает в орнаментальных сюжетах повседневную жизнь и чаяния китайского народа об изобилии и счастье, а значит через орнаментальные мотивы китайцы желают блага ближним и друзьям. Традиционно в модели благопожелательных композиций в технике цзяньчжи обязательно содержится иероглиф «счастье», либо дважды повторяющийся иероглиф 喜 $(x i)$ - «двойное счастье», оба иероглифа могут являться самостоятельной композицией, поскольку входят в состав десяти иероглифов, имеющих сакральное, охранительное значение, а также становиться частью сложно орнаментированных сюжетов «Времена года», «Новогодние благопожелания».

Композиция может состоять из нескольких цельно вырезанных частей, а может быть вырезанной из одного листа. Особенность состоит в том, что рисунок делается на основе непрерывной прорези, она переходит в композиционные элементы, с еѐ помощью передаѐтся объѐм и фактура, так создаѐтся эффект «бумажного кружева». Бумажные полоски выполняют ту же функцию, что и штрих карандаша. Поэтому используются ножницы малых размеров с большими круглыми ручками. Этот инструмент может передаваться из поколения в поколение, от мастера к мастеру, храня «опыт» предыдущего владельца. Техника вырезания ножницами 
наиболее сложна, поскольку требует высочайшего мастерства и художественного вкуса. Вырезают также и с помощью ножа, так можно проработать более мелкие детали. Для создания симметричных композиций с помощью резцов используется «принцип снежинки»: бумагу складывают в несколько раз, наносят контур узора или рисунка, а затем вырезают. Предварительно стопку бумаги в несколько десятков листов в зависимости от сорта кладут на доску, которая для мягкости предварительно смазывается смесью животного жира и золы, закрепляют бумагу гвоздями. Мастер держит нож строго перпендикулярно поверхности, благодаря этому линии получаются тонкими и плавными. Основные приѐмы для создания прорезей ножницами или ножом - это «зубья» и «полумесяцы» [2, с. 99]. В первом случае мастер, меняя конфигурацию «зубьев», передаѐт облик изображаемого. К примеру, острые зубцы используются для того, чтобы показать шерсть, щетину, а плавные полуарочные - для рыбьей чешуи и перьев птиц. Приѐм «полумесяцев» применяется для изображения складок, украшений. Эти элементы мастер умело сочетает в изображении облаков, волн и орнаментальных завитков. Прорези служат композиционным фоном. В большинстве своѐм сюжеты цзяньчжи выполнены из бумаги красного цвета, ведь в традиции китайского народа красный цвет, прежде всего, оберег, дарующий счастье и радость, благополучие и долголетие. Поэтому вырезанные ярко-алые благопожелательные иероглифы на окнах, стенах и входных дверях домов - это не только элемент декора, а своеобразная защита от агрессивной среды и бед, настрой на привлечение счастья хозяевам.

Из-за своего назначения - «украшать» ажурными узорами окна, подобного рода композиции получили название «窗花》 (“chuanghua”), что переводится как «оконные цветы». Промасленная рисовая бумага на окнах, украшенная узорами, производила эффект витража, особенное изобилие подобных композиций можно увидеть в преддверии Праздника Весны (春节, chunjie), или Китайского Нового года. Благопожелательные орнаментальные композиции активно сопровождают юбилейные торжества и свадебные церемонии.
Наиболее ранние композиции цзяньчжи встречались еще в период Северных династий (386 - 581 гг. н.э.), До того, как Цай Лунь в период правления династии Хань изобрѐл бумагу, в 105 г., вырезали из кожи, серебряной и золотой фольги. Своим расцветом искусство ажурного вырезания обязано династии Тан (618 - 907 гг.), когда Китай достиг наивысшей военной мощи и высокого уровня культуры и искусства, опережая другие страны. Сложные и выразительные по стилистике, детально проработанные композиции приобрели изящество и сложность исполнения (пейзажные, символические, портретные, времена года, цветы и бабочки, любовные и мифологические сцены, легенды), они иллюстрировали литературные произведения поэтов и писателей. Существуют композиции с изображением героев пекинской оперы, ещѐ одного наследия китайской культуры, всех четырѐх амплуа - чоу, дань, цзин, шэн (Puc.1). Одним из наиболее часто изображаемых персонажей является Чжан Фэй, герой романа «Троецарствие». В не столь давнее время появились портретные композиции, изображающие известных политических, общественных и культурных деятелей. Это, скорее, влияние западной культуры. Данные работы имеют наибольшее сходство с плакатным жанром или гравюрой - декоративность и реалистичность образа существуют в них едино, применяются схожие эффекты светотени. Жанр портрета в искусстве цзяньчжи носит название 人物 (ren wu). Поскольку в композиции цзяньчжи не может быть разрывов, то мастер подчиняет еѐ красоте рисунка и сознательно стилизует изображаемое. Данную стилизацию можно проследить главным образом в форме лица, в соединении деталей головных уборов или причѐски $\mathrm{c}$ его составляющими. Мастеру удаѐтся создать удивительно живой образ, при этом, не нарушая его гармоничность. В сельской местности это искусство считалось грубоватым и прозаичным, с сюжетами, воспевающими труд простого человека, крестьянина. В народе вырезание из бумаги считалось женским видом искусства, как основа (трафарет) для подготовки композиций в технике цзяньчжи под украшение одежды ручной вышивкой.
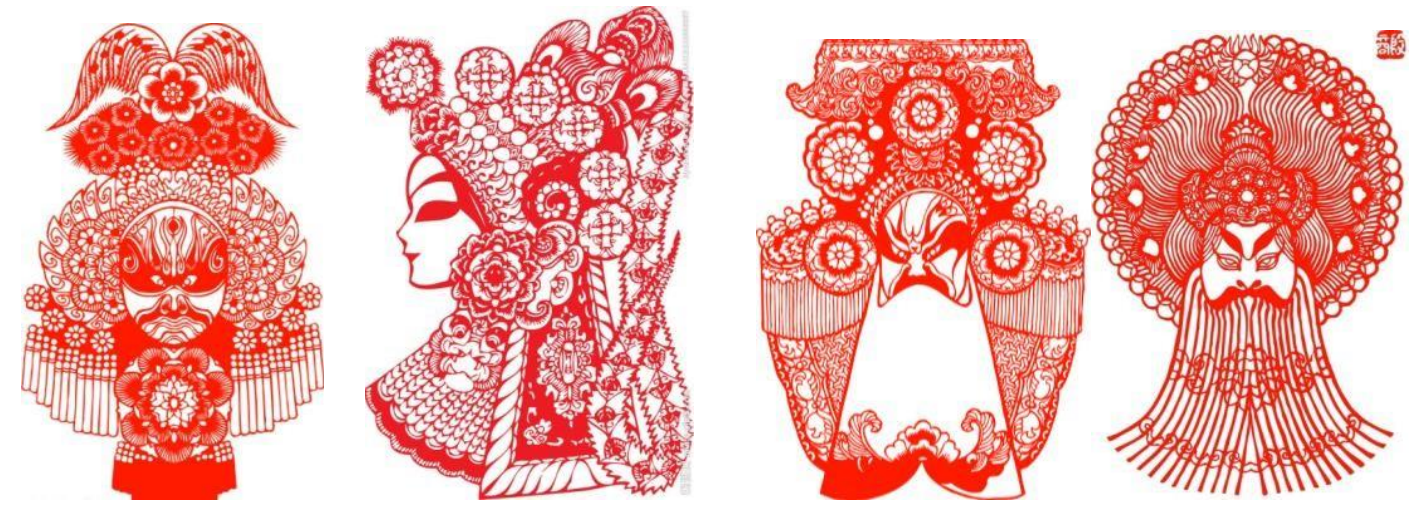

Рис. 1. Лики пекинской оперы. По материалам сайта www.nipic.com 
Крестьянские девушки с ранней юности готовили для себя приданое, и по мастерству (качеству и красоте) исполнения цзяньчжи, сваты судили о трудолюбии и уме невесты, будущей жены и матери. Несмотря на эту особенность, сегодня встречается множество мастеров-мужчин, дипломированных художников, потому как это искусство преподаѐтся на факультетах традиционного искусства, и в системе непрерывного образования всех ступеней, а также входит в программу дополнительного образования. Поэтому это искусство в наши дни приобрело, всекитайские масштабы и по-прежнему, является самым популярным в жизни народа.

Каждому региону Китая характерен собственный стиль цзяньчжи. Так, на севере страны вырезание из бумаги монолитно и грубовато, а на юге более ажурное - «иньское» и «яньское» трафаретное вырезание, преимущественно распространѐнное в провинции Фуцзянь. [2, с. 99], Такие композиции создаются путѐм вырезания просветов в цельной полоске бумаги и применяются в качестве трафарета для росписей или резьбы по дереву. В городе Нанкин, провинции Цзянсу распространѐн стиль «Птицы и цветы», которых вырезают с помощью резцов. В городе Тяньцзинь распространѐн стиль «Цветы и бабочки», вырезают в комбинированной технике (ножницы и резцы). В провинции Хэбэй мастера пользуются техникой вырезания, схожей с новогодним лубком няньхуа. Изготавливаются такие работы из очень тонкой рисовой бумаги, на которую затем точечными мазками наносится краска. На месте касания кисти образуется густое цветовое пятно, края которого переходят в изящный полутон, высвеченный чистотой белого. Последующие слои наносятся только после окончательного высыхания краски. Это разнообразие стилей создаѐт уникальный образ народного искусства цзяньчжи, но вот мастеров, знающих его в традиционном виде, осталось около трѐх десятков по всей стране, а их средний возраст составляет 60-70 лет. Поэтому вопрос о сохранении искусства цзяньчжи, как традиционного вида декоративно-прикладного искусства на сегодняшний день стоит наиболее остро. Великие мастера рождаются и уходят, оставляя после себя богатое наследие и собственный стиль, который даѐт новое понимание народному творчеству.

Одним из таких великих мастеров по праву можно считать Ку Шулан (1920 - 2004). Она принадлежала к числу бедных крестьян, но совершила прорыв в уже общепринятой модели искусства цзяньчжи, создав свою уникальную технологию и сюжетную линию бумажных композиций. Ку Шулан родилась в маленькой деревне уезда Сюньи провинции Шэньси. Еѐ жизнь похожа на судьбу многих китайских женщин того времени: в 9 лет мать забинтовала ей ноги, поскольку «лотосовые ножки», считались идеалом женской красоты. Получив начальное образование, девочка стала учиться вышиванию и цзяньчжи у местных мастериц. В возрасте 17 лет вышла замуж. Ранней весной 1985 г. случилась беда: в результате падения с обрыва Ку Шулан получила множественные травмы и впала в кому на 40 дней. Еѐ семья уже приготовилась к худшему, но она неожиданно пришла в себя. После этого она будто «прозрела», у нее появился дар создания удивительно сложных и гармоничных композиций из бумаги, интересных по сюжетам и цвету. Еѐ работы воспевают красоту, элегантность и величие женщины.
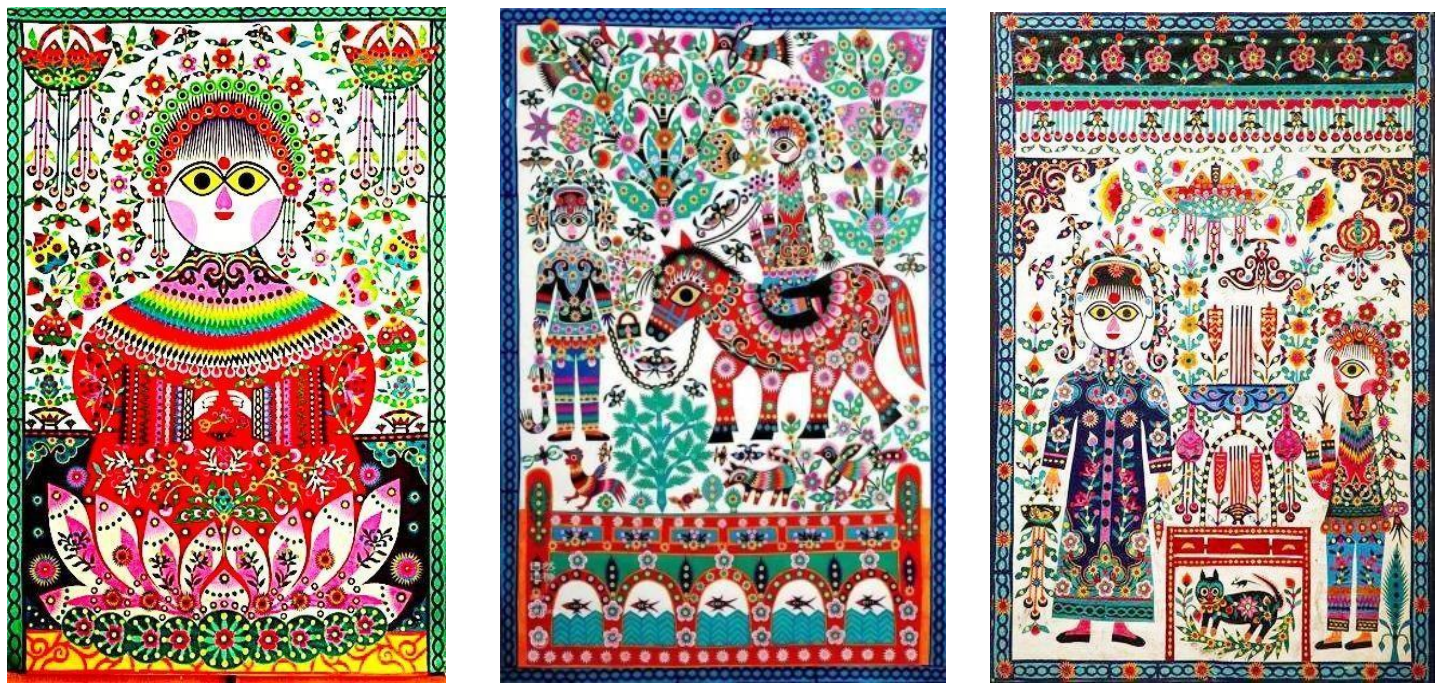

Рис.2. Ку Шулан. Богиня вырезания из бумаги. Цзянва ведёт лошадь, пока Мэйсян едет.

Об этом повествует одна из еѐ лучших и самых известных работ, созданная на пике «карьеры»это «Богиня вырезания из бумаги» (《剪花娘子», “Jianhua Niangzi”). Творчество мастерицы неразрывно связаны с народными песнями. Она использует их тексты, чтобы выразить «песни своего сердца» в ажурных многоярусных вырезках [5]. Произведение «Цзянва ведѐт лошадь, пока Мэйсян едет» (《江娃拉马梅香骑》, “Jiangwa la ma Meixiang qi”) рассказывает истории о судьбе супружеской пары (Рис.2). В сюжете этой работы царит идиллия и счастье, множество райских 
цветов и птиц окружают героев. Мастерица, вырезая композицию, пела, описывая сцены флирта молодожѐнов на пути невесты в новый для нее дом жениха, песня значительно обогащает содержание работы, давая зрителю лучшее понимание сюжета. Во многих сюжетных сценах работ Ку Шулан, отражена борьба жизни и смерти. Ее работы не прямой образ, это ассоциации, благодаря чему зритель имеет возможность «домыслить» каждый сюжет и увидеть в изображѐнном что-то свое. Многие работы мастерицы, соединяясь с поэтичностью и эмоциональной визуальностью, пробуждают живую и динамичную мелодию песни народной жизни. Ку Шулан обычно использовала цветную вощѐную бумагу. Еѐ работы выходят за рамки традиционной монохромной модели цзяньчжи. Ее метод вырезания экспрессивен, благодаря двумерному изображению, где делалась черная или тѐмного цвета основа, которая дополнялась светлыми и яркими узорами. Данный приѐм создавал эффект объѐма, похожий на искусство теневого театра. Она особенно использует этот приѐм в комплементарности цветовых переходов, передавая композиционное пространство. При жизни еѐ творчество было высоко оценено организацией UNESCO. В марте 1996 года Ку Шулан было присвоено высокое звание Мастера народного искусства и промыслов Китая (в истории страны этого звания удостоились лишь пять человек). В 2001 г. работы Ку Шулан участвовали в Международной выставке искусства Объединѐнных Наций и получили широкий отклик общественности. В 2003 г. Издательским домом изящных искусств выпустил книгу о жизни мастера: «Ку Шулан: легенда Богини вырезания из бумаги», затем книга была растиражирована по всему Китаю. Но, несмотря на мировую известность, жизнь мастера не изменилась. «Лотосовые ножки» причиняли ей нестерпимую боль, а жизненные испытания, закаляли ее, не позволяя потерять надежду на лучшую жизнь. Еѐ «Богиня цзяньчжи» - высочайшая внутренняя чистота простой китайской крестьянки, она помогала ей преодолеть горе [5]. В 1984 г. был создан зал памяти великому мастеру. Ку Шулан получила признание при жизни, что весьма ценно для художника. В экспозицию мемориальной выставки входит более 6000 работ.

Студентка факультета искусств, рекламы и дизайна ТОГУ, Линь Аоцзин, посетив мемориальный музей искусства Ку Шуллан, прониклась уважением мастеру, и решила рассказать о ее творчестве, создав дизайн настольного календаря, в котором представлены ее работы. Благодаря этому проекту, по мнению студентки, посетители постоянно действующей выставки смогут «забрать с собой на память» радостную атмосферу царствующей красоты цвета и наивного стиля, запечатленного в великой истории простого гражданина Китая. Картины Ку Шулан - диалог с вечным, обращаясь к народному сознанию посредством художественных образов, они выражают суть феномена народного искусства «цзяньчжи». Гении народного творчества, мастера, опираясь на глубинные знания предков, являют своим искусством живую нить времѐн (Рис.3).
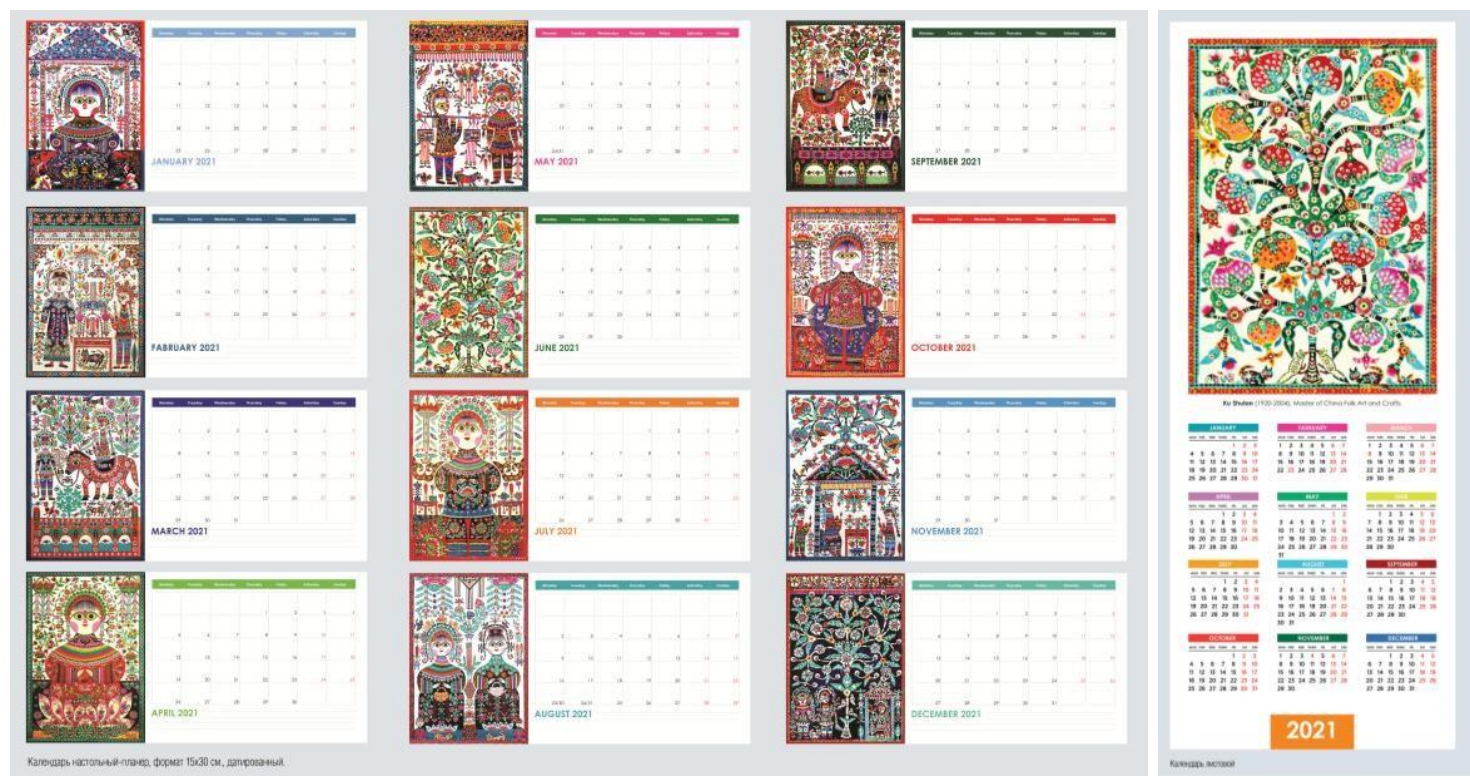

Рис. 3. Дизайн настольного перекидного календаря с работами Ку Шулан. Учебньй проект: студентка 3 курса направления бакалавр дизайна Линь Аочзин; научный руководитель: Мартынов В.В., дочент Тихоокеанского государственного университета, г. Хабаровск.

В настоящее время история искусства цзяньчжи претерпевает изменения, и это справедливо, ведь живое искусство развивается в ногу со временем. Композиции из бумаги становятся воздушнее, ажурнее, благодаря современным технологиям выходя на новаторский этап, они активно используются в индустрии моды, вдохновляя художников и дизайнеров на оригинальные и смелые идеи в декоре ширм, подарков, сувенирной продукции и предметов 
быта. Модельеры все активнее используют прорезные ткани, декор в одежде и головных уборах сродни искусным вырезкам из бумаги. Ажурно обрабатываемый художником металл старых бочек обретает ценность неповторимых уличных АРТ-объектов.

Обобщая все вышесказанное, выделим структурно-содержательные особенности китайского искусства ажурного вырезания из бумаги:

1. Искусство цзяньчжи представляет собой один из древнейших видов народного искусства с функцией благопожелательных символов. Наиболее частыми сюжетами являются как мифопоэтические образы (дракон, птица ФенХоан, черепаха, журавль) так и отдельные иероглифы-символы китайского языка.

2. Сюжеты цзяньчжи воспевают объективную действительность, жизнь простого народа, а народные мастера, с помощью незамысловатых художественных приѐмов, создают уникальные красочные композиции, отражающие оптимизм и экспрессивность китайской нации.

3. География Китая обусловливает многообразие стилей искусства вырезания из бумаги, что делает его ещѐ более самобытным.

4. Искусство цзяньчжи распространено в масштабах страны, оно активно внедряется в современные течения искусства и дизайна, его изучение ведѐтся повсеместно и среди всех слоѐв населения, благодаря чему формируется знание традиционной культуры и уважение к народным промыслам среди всех возрастов. Феномен
Искусство цзяньчжи является «культурным кодом» Поднебесной, еѐ «фирменным стилем», позволяющим возвысить духовное богатство древней нации, многовековой опыт, самобытность и красоту народной культуры, сделав еѐ узнаваемой среди разнообразия культур Мира.

\section{Список литературы References}

1. Орнамент всех времѐн и стилей. В 2 томах / Б.Б. Павлов, Т.И. Хлебнова, В.Ф. Иваницкий. - М. : «АРТ-РОДНИК». Том 1, 2004.

2. Петриченко А.А. Узоры и силуэты из бумажного листа // Домодедовский историкохудожественный музей, 2007.

3. Искусство вырезания из бумаги в культуре мира [Электронный ресурс] Академия современного искусства и дизайна ТОГУ http://artacademy-khv.ru/interesting-1 (дата обращения: 13.05.2020).

4. Поэзия цзяньчжи [Электронный ресурс] Журнал «Китай» http://www.kitaichina.com/rwenhua/201901/t2019011 1_800154085.html (дата обращения: 13.05.2020).

5. $\mathrm{Ku}$ Shulan, Goddess of Paper Cut [Электронный pecypc] TsemRinpoche https://www.tsemrinpoche.com/tsem-tulkurinpoche/art-architecture/ku-shulan-goddess-ofpapercut.html (дата обращения: 11.05.2020).

6. 中国国际广播电台 China Radio International [Электронный pecypc] http://chinaplus.cri.cn/ (дата обращения: 14.05.2020). 